\title{
Erratum to: Variants within the $M M P 3$ gene and patellar tendon properties in vivo in an asymptomatic population
}

\author{
Brandon Paul Foster • Christopher I. Morse • \\ Gladys L. Onambele $\cdot$ Alun G. Williams
}

Published online: 26 February 2015

(C) Springer-Verlag Berlin Heidelberg 2015

Erratum to: Eur J Appl Physiol (2014) 114:2625-2634

DOI 10.1007/s00421-014-2986-7

Unfortunately, one of the affiliations of the co-author, Alun G. Williams, has been missed in the original publication of the article. The correct information is as follows:

Alun G. Williams

Institute for Performance Research, Manchester Metropolitan University, Crewe CW1 5DU, UK

The online version of the original article can be found under doi:10.1007/s00421-014-2986-7.

B. P. Foster ( $\bowtie)$

Maternal and Fetal Health Research Group, Institute of Human

Development, University of Manchester, St. Mary's Hospital,

5th Floor, Oxford Road, Manchester M13 9WL, UK

e-mail: brandon.foster-2@manchester.ac.uk

C. I. Morse · G. L. Onambele · A. G. Williams

Institute for Performance Research, Manchester Metropolitan

University, Crewe CW1 5DU, UK

A. G. Williams

Institute of Sport, Exercise and Health, University College

London, London, UK 